\title{
Rheological behaviour of submicron mullite-carbon nanofiber suspensions for Atmospheric Plasma Spraying coatings
}

\author{
D. Rodríguez ${ }^{\text {a, }}$, I.G. Cano ${ }^{\text {a }}$, J. Fernández ${ }^{\text {a }}$, J.C. Fariñas ${ }^{b}$, R. Moreno ${ }^{b}$ \\ ${ }^{\text {a }}$ Thermal Spray Center (CPT), Universitat de Barcelona, 08028 Barcelona, Spain \\ ${ }^{\mathrm{b}}$ Instituto de Cerámica y Vidrio, CSIC, 28049 Madrid, Spain
}

Received 15 May 2013; received in revised form 18 July 2013; accepted 22 July 2013

\begin{abstract}
Mullite is widely used as a structural material for applications like thermal and environmental barriers coatings. For some of these applications, thermal spray is a suitable technique due to its fast production time and versatility. This makes mullite a very interesting coating material for thermal spray industry. In the present work, the viability to produce coatings by thermal spray using mullite-CNFs agglomerated powders is analyzed. The stability of aqueous mullite and mullite-CNFs suspensions was studied in terms of zeta potential and rheological behaviour of concentrated slurries. Slurries were optimized in terms of dispersant concentration and solid content. The optimized suspensions were used for the granules preparation by spray drying technology. The obtained granules were characterized through the determination of particle size distribution and shape factor by field emission scanning electron microscopy and laser scattering. These granules were used to form the coatings by Atmospheric Plasma Spraying which were characterized by evaluating the composition, structure, shape, and thickness.
\end{abstract}

(C) 2013 Elsevier Ltd. All rights reserved.

Keywords: Suspensions; Rheology; Mullite; CNF; Thermal spray coatings

\section{Introduction}

There is a broad body of work dealing with the design and fabrication of aluminosilicate-based materials (within the $\mathrm{Al}_{2} \mathrm{O}_{3}-\mathrm{SiO}_{2}$ system) which have received great attention due to their high potential as catalyst supports, catalysts for industrial processes, substrates for electronic devices, and coatings in advanced materials applications. In particular, among the various aluminosilicate phases, mullite $\left(3 \mathrm{Al}_{2} \mathrm{O}_{3}-2 \mathrm{SiO}_{2}\right)$ has been found to possess many of the properties - such as low thermal expansion and conductivity, low dielectric constant, excellent creep resistance, robust chemical and thermal stability, good high-temperature strength and oxidation resistance - that are required for ceramics for high temperature engineering and electronic packaging applications, or to be used as a matrix for advanced composites. ${ }^{1-4}$ The enhanced properties achieved for mullite-based coatings make mullite to be a brave candidate to

\footnotetext{
* Corresponding author. Tel.: +34 934034449.

E-mail addresses: igcano@cptub.eu, davidorrodriguezvidal@gmail.com (D. Rodríguez).
}

improve materials by proper surface engineering control. However, the main limitation of mullite coatings onto metals comes from the relatively high tendency to cracks formation. ${ }^{5}$ The spontaneous cracking can be associated to two main reasons. The first one is the higher thermal expansion coefficient of the metal substrate. The second one is related to the intrinsically brittle nature of mullite.

Reinforced mullite materials have been largely studied in the past, by introducing either oxides $\left(\mathrm{Al}_{2} \mathrm{O}_{3}, \mathrm{ZrO}_{2}\right.$, etc.) or non oxides $\left(\mathrm{Si}_{3} \mathrm{~N}_{4}, \mathrm{SiC}\right.$, etc.). ${ }^{6,7}$ In this way, the current development of carbon nanofibers (CNFs) have supposed a revolution in the design of reinforcing mechanisms for ceramics, and opened new paths to improve mechanical properties in ceramics. ${ }^{8}$ CNFs are carbon materials that present a cylindrical shape similar as carbon nanotubes (CNTs) but with differential structural and textural characteristics, diameters in the range of $100-200 \mathrm{~nm}$, length up to $500 \mu \mathrm{m}$ and bundles with a diameter less than $1800 \mu \mathrm{m}$. One positive characteristic of CNFs with respect to CNTs is the easier production technology existing for the former. ${ }^{9}$ However, unmodified CNFs are subjected to aggregation into packed ropes or entangled networks due to the strong inter-fibber van der Waals attraction, ${ }^{10-12}$ which acts as 
an obstacle to applications and constitutes the main concern of this study. Different approaches have been proposed to improve the dispersion of CNFs into ceramic matrices such as the use of ultrasounds in diluted suspensions, milling techniques, functionalization by chemical routes, colloidal processing or sol-gel technology. ${ }^{13-16}$ In addition to aggregation problems, CNFs themselves cannot be sprayed by Thermal Spray techniques because they will be burn-out at the spraying temperature.

In the present work, owing to the difficulty to prepare mullite by sol-gel techniques, a micron-sized mullite powder has been selected as starting material. This powder has been attrition milled down to a submicronic size. It is well know that submicron powders could not be directly applied for thermal spraying process due to their poor fluidity and low packing density. Therefore, the preparation of a suitable feedstock containing submicron sized particles for thermal spray requires their controlled agglomeration by spray drying methods and, in some cases, the consolidation of such agglomerates by a thermal treatment, this being the so-called reconstitution process. ${ }^{17-19}$ The aim of the present work was to prepare homogeneous CNFsreinforced mullite suspensions suitable for granules production in order to obtain coating using Atmospheric Plasma Spraying (APS). For this purpose, milled mullite powders were mixed with CNFs to obtain concentrated aqueous suspensions, whose stability was optimized in terms of their rheological behaviour. Optimization from slurries was made by adjustment of additive content and solid content. Agglomerates from CNFs-mullite suspension were produced by spray-drying and used for coating production by APS technique.

\section{Experimental}

\subsection{Starting raw materials}

Mullite powder (MUBS) with nominal stoichiometry $3 \mathrm{Al}_{2} \mathrm{O}_{3}: 2 \mathrm{SiO}_{2}$, and composition 0.1 wt. $\% \mathrm{Fe}_{2} \mathrm{O}_{3}, 0.1$ wt. $\% \mathrm{CaO}$ and $0.4 \mathrm{wt} \% \mathrm{NaO}$ was used in this study. This powder was obtained by electric arc and was supplied by Elfusa Trading SL (Málaga, Spain). Mullite powder was attrition milled in water using alumina jar and alumina balls of $5 \mathrm{~mm}$ in diameter. After milling, powder was dried for $6 \mathrm{~h}$ at $80^{\circ} \mathrm{C}$ till constant weight.

CNFs were supplied by Grupo Antolin Ingeniería (Burgos, Spain). CNFs were manufactured by vapour phase growth, ${ }^{20}$ through decomposition of hydrocarbons in the gas phase in the presence of catalytic particles of nickel. Grupo Antolin Ingeniería has a patent about the product as GANFs carbon nanofibers. From manufacturing process, nickel impurities are observed in final CNFs.

\subsection{Colloidal behaviour}

The colloidal stability of aqueous suspensions of mullite and CNFs was studied by measuring the zeta potential as a function of $\mathrm{pH}$ and deflocculant content using a Zetasizer NanoZS instrument (Malvern, UK), based on the laser Doppler velocimetry technique. $\mathrm{HCl}$ and $\mathrm{KOH}$ were used to change the $\mathrm{pH}$, and $\mathrm{KCl} 10^{-2} \mathrm{M}$ was used as an inert electrolyte. An ammonium salt of Polyacrylic Acid (PAA) was used as a deflocculant with additions of $0.5,0.8,1.0$, and $1.5 \mathrm{wt} . \%$ (on a dry solids basis). No binders were added to avoid the presence of undesired organic compounds in the final structure of the granules, as this can be deleterious or can complicate further processing steps. Suspensions for zeta potential measurements were prepared to a powder concentration of $10^{-1} \mathrm{~g} / \mathrm{l}$ and sonicated for $1 \mathrm{~min}$ with an ultrasound (US) probe (UP 400S, Dr. Hielscher GmbH, Germany) in order to prevent agglomeration. Measurements were performed on the fresh, as-prepared suspensions.

\subsection{Rheological study}

Concentrated milled mullite suspensions with solids loadings of 30 and 40 vol.\% and different contents of PAA $(0.8,1.0$ and $1.5 \mathrm{wt} . \%)$ were prepared. Concentrated suspensions of milled mullite/CNFs mixtures were also prepared with solids loadings of 30 and $40 \mathrm{vol} . \%$ and different contents of PAA $(0.8,1.0$ and $1.5 \mathrm{wt} . \%$ ) using relative contents of CNFs of 1 and $2 \mathrm{wt} . \%$ with respect to mullite mass. The rheological behaviour of all prepared slurries was performed with a rheometer (Haake RS50, Thermo, Germany) operated at controlled shear rate (CR) conditions. The sensor system consisted on a double-cone rotor (with a cone diameter of $60 \mathrm{~mm}$ and cone angle of $2^{\circ}$ ) and a stationary plate, this system being surrounded by a cylindrical wall. The chamber is protected with a solvent trap to reduce evaporation phenomena. Measurements were performed by increasing the shear rate from 0 to $1000 \mathrm{~s}^{-1}$ in $5 \mathrm{~min}$, maintaining at $1000 \mathrm{~s}^{-1}$ for $2 \mathrm{~min}$ and returning to 0 in $5 \mathrm{~min}$. Temperature was maintained constant at $25^{\circ} \mathrm{C}$.

\subsection{Granulation}

Optimized suspensions were spray dried by a NIRO Mobile Minor atomizer (GEA NIRO, USA) to obtain granules. This atomizer evaporated a maximum volume of $7 \mathrm{~kg}$ water $/ \mathrm{h}$. Suspension was sprayed by a pneumatic nozzle placed at the bottom of the apparatus. A nozzle diameter of $2 \mathrm{~mm}$ and air pressure of 0.8 bars were chosen as spray drying parameters.

\subsection{Thermal spray}

As-obtained agglomerates were thermal sprayed using an APS A-3000S system with an F4 plasma torch (Sulzer Metco, Germany) with a theoretical plasma temperature of $11,000{ }^{\circ} \mathrm{C}$, spraying distance of $120 \mathrm{~mm}$ and cooling at room temperature. Five layers were deposited on a 3061 steel substrate. Spraying conditions were 35:13 1/min Ar:H2 gas ratio with $4.51 \mathrm{Ar} / \mathrm{min}$ gas flow, at $120 \mathrm{~mm}$ and an intensity of $600 \mathrm{~A}$.

\subsection{Characterization techniques}

The physico-chemical characterization of initial and milled mullite powder was performed by measuring the particle size distribution, by using the laser diffraction (LD) technique (LS 13320, Beckman Coulter, USA), and the specific surface area, which was determined using the single-point BET method 
(MonosorbTM Surface Area Analyzer MS-13, Quantachrome Corporation, USA) after degassing at $150^{\circ} \mathrm{C}$. Average sizes were taken as the median value of the cumulative curves of particle size versus particles volume fraction. Densities were measured by He-pycnometry (Quantachrome Corporation, USA).

Particle size distribution of CNFs was obtained by dynamic light scattering (DLS, Analysette 12 DynaSizer, Fritsch, Germany) using diluted suspensions $\left(10^{-2} \mathrm{~g} / \mathrm{l}\right)$. This technique was used as a rough estimation due to their elongated shape very far from the sphericity assumed by diffraction techniques. However, this estimation can be assumed considering that CNFs randomly agglomerate into more or less rounded clusters. Particle size distribution of spray dried powder was attained by LD. Carbon content in spray dried powder was determined by using a elemental organic analyzer Thermo EA 1108 (Thermo Scientific, Milan, Italy) working at $120 \mathrm{ml} / \mathrm{min}$ helium flow, combustion furnace at $1000^{\circ} \mathrm{C}$, chromatographic column at $60^{\circ} \mathrm{C}$ and $10 \mathrm{ml}$ oxygen loop at $100 \mathrm{KPa}$.

Phase composition of initial and milled mullite powder, spray dried powder and thermal sprayed coatings was determined by X-ray diffraction (XRD) using a diffractometer PANalytical X'Pert PRO MPD (model DY 3197, The Netherlands). The XRD patterns of orthorhombic Aluminium Silicon Oxide, Mullite (PDF 01-073-1253), tetragonal Silicon Oxide, Silica (PDF 00-045-1374), hexagonal Carbon, Graphite (PDF 00-001-0646), rhombohedral Aluminium Oxide, Alumina (PDF 01-075-1862), and face-centred cubic Nickel, Nickel (PDF 00-001-1258) collected at the $\mathrm{ICDD}^{\odot}$ databank (JCPDS-The International Centre for Diffraction Data ${ }^{\Theta}$, Newton Square, PA, USA) were used as references for the analysis of our XRD patterns.

The morphology of initial and milled mullite powder, CNFs, and spray dried powder were studied by field emission scanning electron microscopy (FE-SEM, Hitachi S-4700, Japan). FESEM was also used for the characterization of thermal sprayed coating.

The adhesion of the coatings was measured according to ASTM-C633 F1000 procedure, using adhesive wafers. The specimens were coated with a bonding sample with similar degree of roughness of the samples screened, and were treated at $165^{\circ} \mathrm{C}$ for $5 \mathrm{~h}$, maintaining a constant pressure of $70 \mathrm{~N}$ to maintain unity. Once treated and cooled, the breaking strain of the samples was measured. For measuring the breaking stress of the coating, a tensile testing machine Servosys MCH-102ME (Servosys, USA) of $10 \mathrm{kN}$ was used. The maximum load is the breaking load.

\section{Results and discussion}

\subsection{Characterization of mullite and CNFs}

Starting mullite powder had an average particle size of $0.69 \mu \mathrm{m}$, a surface area of $53 \mathrm{~m}^{2} / \mathrm{g}$, and a density of $3.04 \mathrm{~g} / \mathrm{cm}^{3}$ after milling process. Fig. 1 shows the XRD of both the mullite powder before (Fig. 1a) and after (Fig. 1b) milling, and the CNFs (Fig. 1c). As can be seen in Fig. 1a and b, the main phase is orthorhombic mullite, although the presence of residual silica

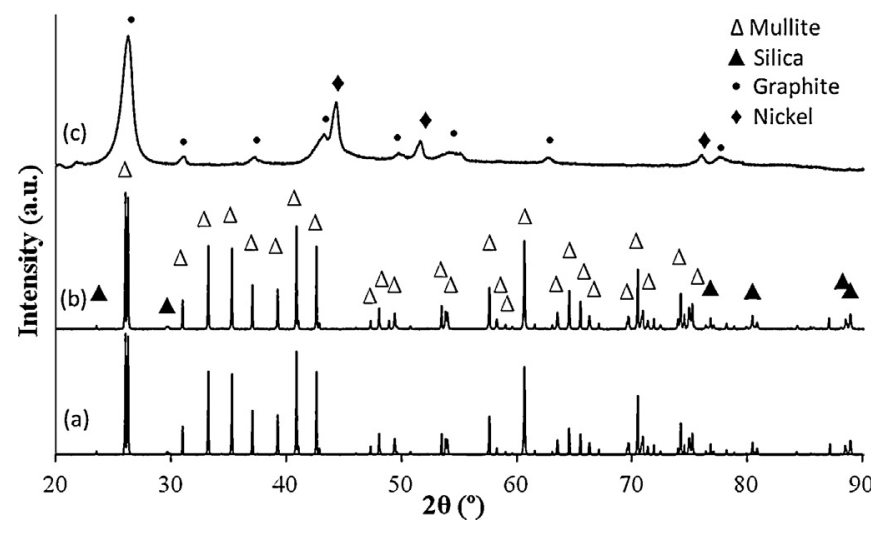

Fig. 1. XRD patterns of (a) as-received and (b) milled mullite powders and (c) CNFs.

is still detected. As observed in Fig. 1c, intense peak at $26.1^{\circ} 2 \theta$ angle determines plane [0 02 2] of hexagonal graphite associated with the CNFs by shifted position. Peaks at $44^{\circ}, 51.5^{\circ}, 76^{\circ}$, and $92.5^{\circ} 2 \theta$ angle confirm the presence of nickel. Peaks at $55^{\circ}$ and $78^{\circ} 2 \theta$ angle associated with CNFs bundles are observed.

Fig. 2 shows the particle size distribution of the starting powders of submicrometer sized mullite and CNFs measured by LD and DLS, respectively. The particle size distribution of milled mullite (Fig. 2a) shows a bimodal distribution with average sizes of about 0.6 and $2.2 \mu \mathrm{m}$, respectively, and $90 \mathrm{vol} . \%$ of milled mullite particles with a diameter smaller than $4.1 \mu \mathrm{m}$. The CNFs present an average size (Fig. $2 \mathrm{~b}$ ) of about $0.6 \mu \mathrm{m}$ with
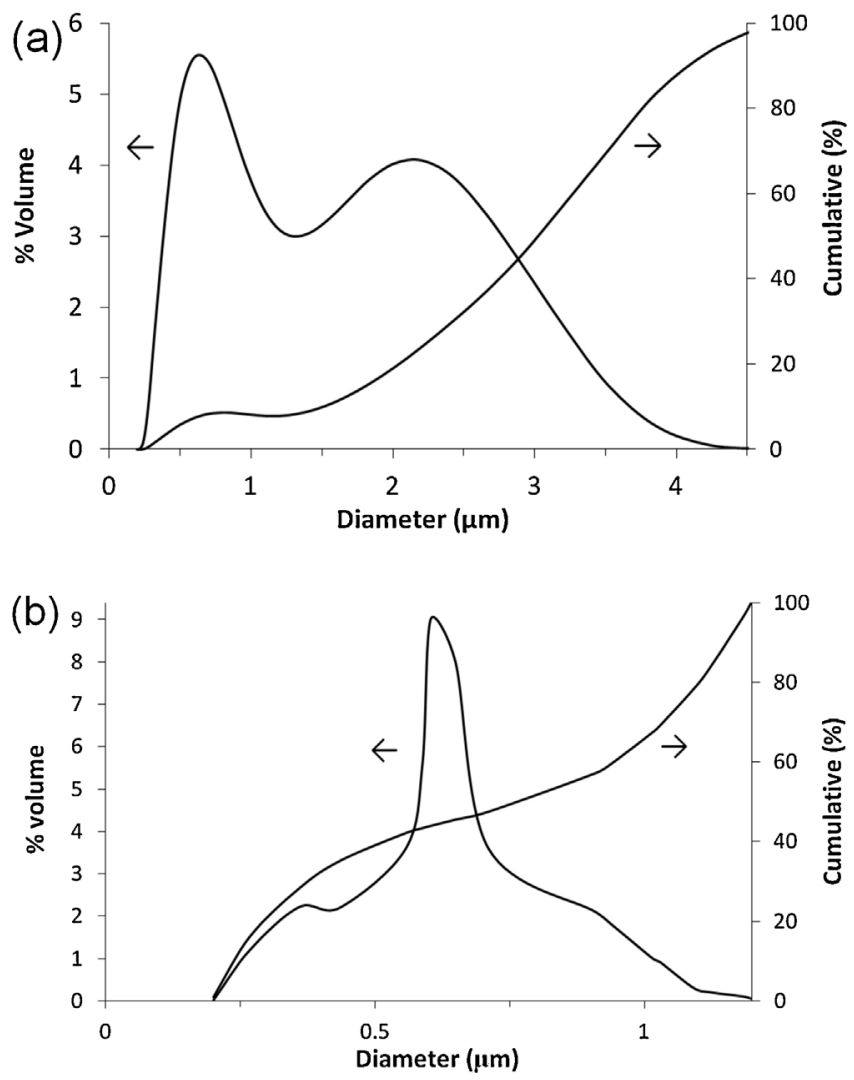

Fig. 2. Particle size distribution of (a) mullite powders and (b) carbon nanofibers measured by LD and DLS, respectively. 

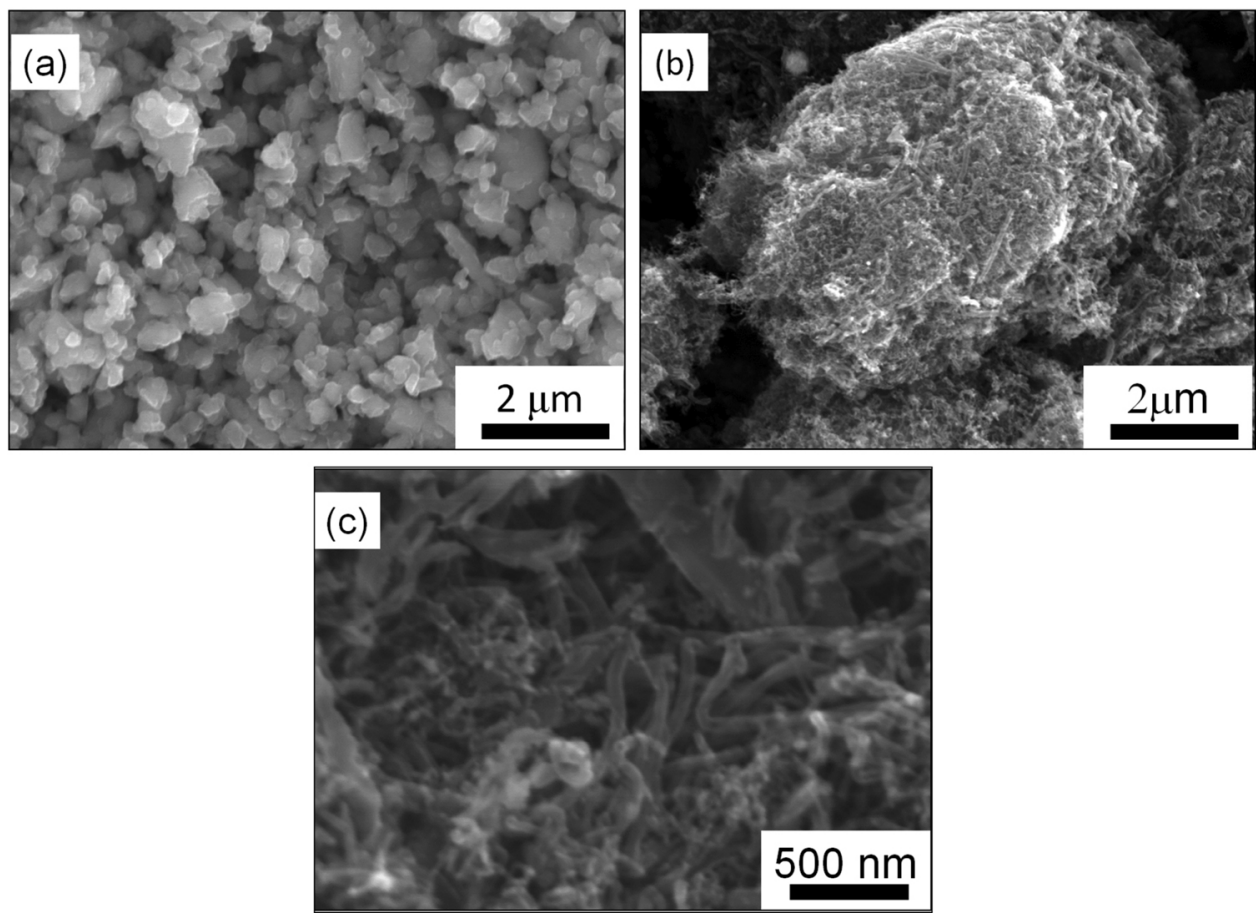

Fig. 3. FE-SEM images of (a) milled mullite powders and CNFs at (b) low and (c) high magnification.

shoulders at 0.35 and $0.7 \mu \mathrm{m}$. This distribution is associated with low CNFs size, shape factor and bundle presence.

Fig. 3 shows the morphology of both the milled mullite powder (Fig. 3a) and the CNFs (Fig. 3b and c). Mullite appears as submicron, faceted powders with some agglomerates of few microns, and CNFs are constituted by fibres and tubes of different sizes forming agglomerates (bundles) with regular shapes. ${ }^{21}$ With regard to CNFs, FE-SEM micrographs (Fig. 3b and c) demonstrated that the particle size is lower than that measured by laser scattering (Fig. 2b). Although laser techniques are not adequate for measuring non-spherical particles like CNFs, they agglomerate forming nearly spherical clusters with randomly oriented fibres inside, so that laser measurements may be useful to evaluate the size of such clusters and their agglomeration degree. Those measurements reveal a particle size distribution ranging from $200 \mathrm{~nm}$ to $1.2 \mu \mathrm{m}$ (Fig. 2b).

\subsection{Stability of colloidal suspensions of mullite and CNFs}

Suspensions of milled mullite powder and CNFs were prepared in water measuring the variation of zeta potential with $\mathrm{pH}$ and dispersant content in order to explain agglomerates formation and mullite-CNF interactions. The isoelectric point of mullite occurs at pH 3.3 (Fig. 4a). This is lower than typical values reported for other mullite powders, ${ }^{21-25}$ which suggests that the powder has a silica-enriched surface. Large absolute values of zeta potential are obtained at $\mathrm{pH}>5$.

The stability of CNFs was studied by means of zeta potential measurements (Fig. 4a), showing that the isoelectric point occurs at $\mathrm{pH} \approx 3.5$. From those measurements, stable suspensions of mullite-CNFs mixtures could be prepared in water at $\mathrm{pH}>7$, where values of zeta potential of about $-13 \mathrm{mV}$ for CNFs
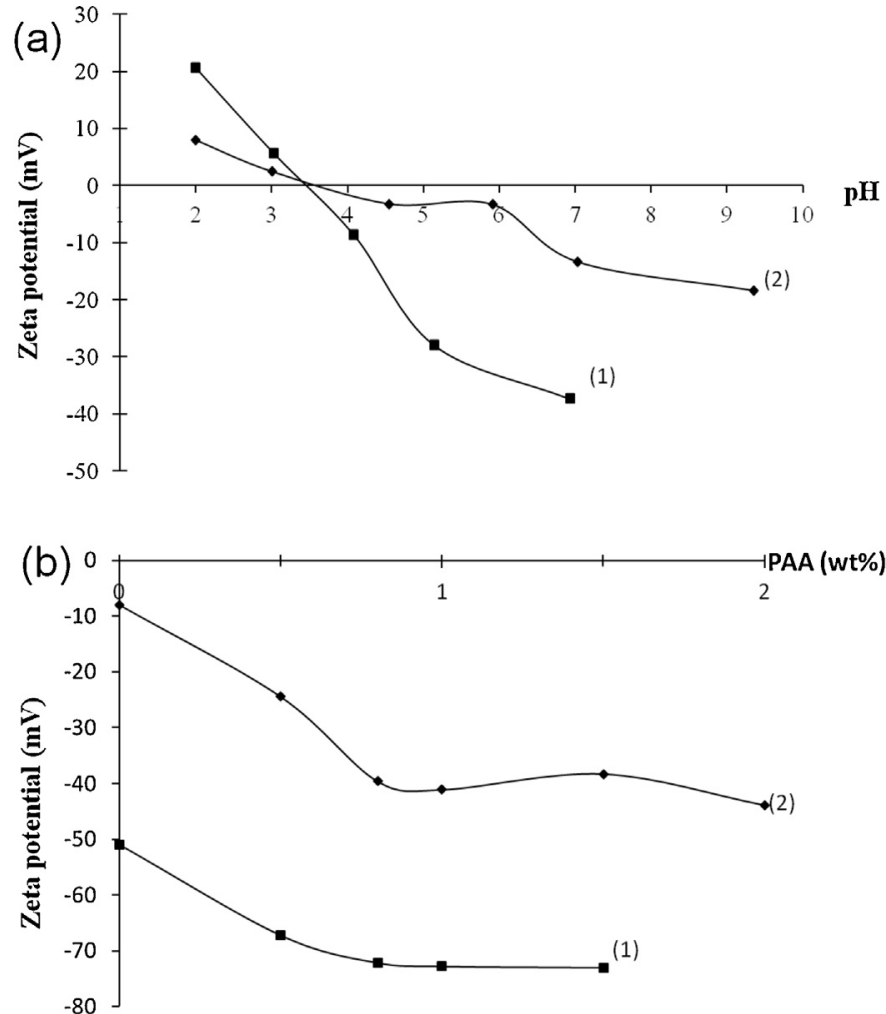

Fig. 4. Variation of zeta potential with (a) $\mathrm{pH}$ and (b) deflocculant content for (1) milled mullite and (2) CNFs.

and $-37 \mathrm{mV}$ for micron-submicron mullite ensure dispersion capability.

In Fig. $4 b$ the variation of zeta potential as a function of polyelectrolyte content is observed for both mullite and CNFs, 

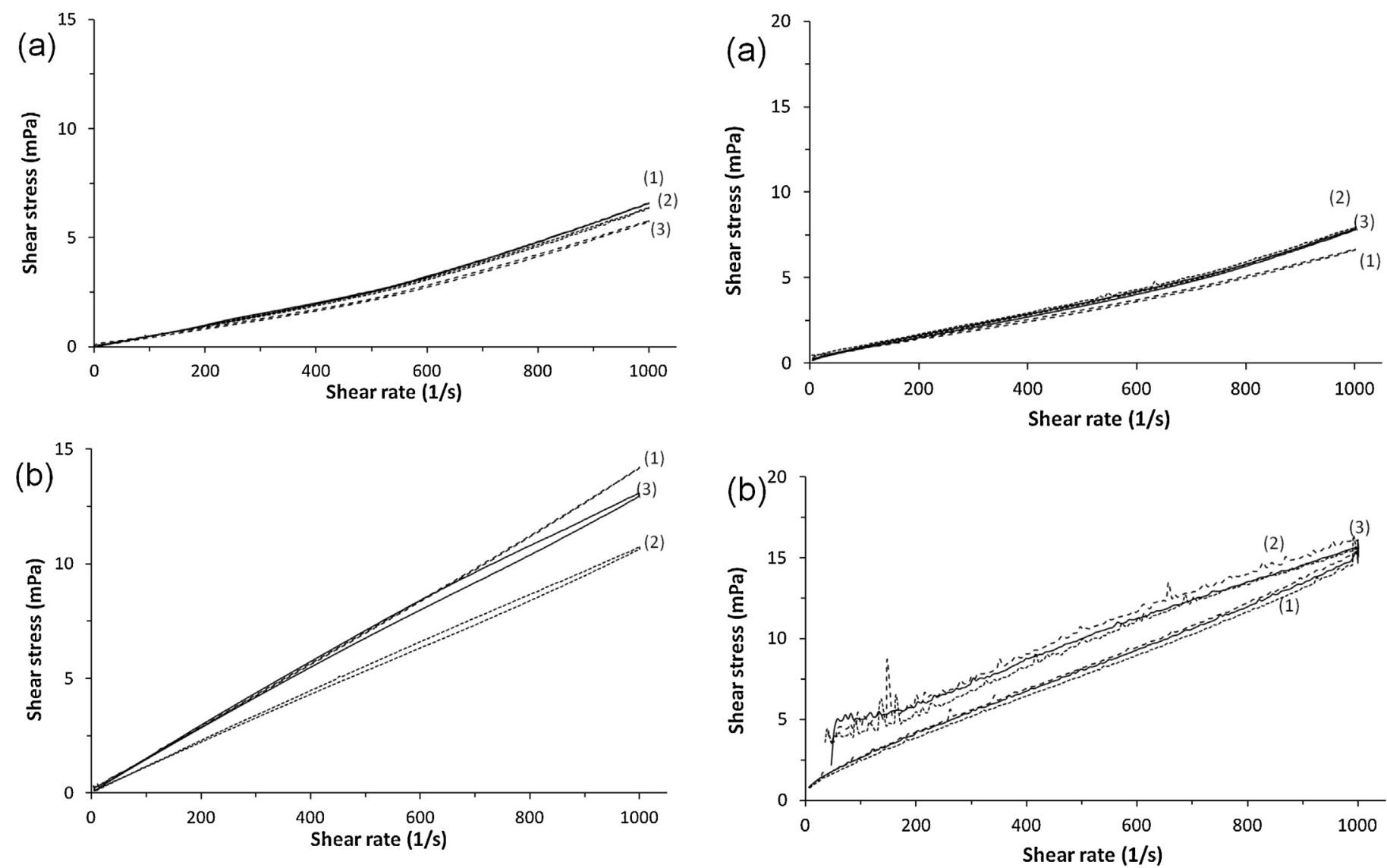

Fig. 5. Flow curves of milled mullite suspensions prepared to (a) 30 and (b) 40 vol. \% solids with (1) $0.8 \mathrm{wt} . \%$ PAA, (2) $1.0 \mathrm{wt} . \%$ PAA, and (3) $1.5 \mathrm{wt} \%$ PAA.

respectively. The behaviour of mullite and CNFs suspensions with respect to PAA additions seems to have the same trend. The absolute value of zeta potential increases adding PAA, until $1 \mathrm{wt} . \%$ PAA. Surface charge stabilization is observed at higher deffloculant content, with absolute values that differ in less than $10 \mathrm{mV}$. Stability is ensured for PAA content of $1 \mathrm{wt} . \%$ as it readily adsorbs onto the surface and shifts down the isoelectric point, as can be deduced from the strong increase of zeta potential absolute values.

\subsection{Rheological study}

Considering that the CNFs will be dispersed in a mullite suspension, the rheological behaviour of concentrated mullite suspensions was first studied. Fig. 5 shows the flow curves of milled mullite suspensions with different contents of PAA ( 0.8 , 1.0 and $1.5 \mathrm{wt} . \%$ ) and solids loadings of $30 \mathrm{vol} \%$ (Fig. 5a) and 40 vol.\% (Fig. 5b). Viscosities are very low even in the most concentrated suspension. However, an increase of deflocculant content is needed as the solids loading increases from 30 to 40 vol.\% solids, the optimum concentrations being 1.5 and $1.0 \mathrm{wt} . \%$ deflocculant, respectively. The less concentrated suspension is nearly Newtonian (or very slightly shear thickening), while the concentrated one is slightly shear thinning and in all cases there is no thixotropy.

Fig. 6. Flow curves of milled mullite-CNFs suspensions with (a) 1 wt.\% and (b) $2 \mathrm{wt} . \%$ of CNFs prepared to 30 vol. $\%$ solids with (1) $0.8 \mathrm{wt} . \%$ PAA, (2) $1.0 \mathrm{wt} . \%$ PAA, and (3) 1.5 wt. $\%$ PAA.

Once the stability conditions for the preparation of suspensions were analyzed for the single components, suspensions of mullite-CNFs were prepared. Fig. 6 shows the flow curves of 30 vol.\% mullite suspensions with $1 \mathrm{wt} . \%$ (Fig. 6a) and $2 \mathrm{wt} . \%$ (Fig. 6b) of CNFs prepared with different deflocculant concentrations. It is observed the effect of CNFs content on thixotropic behaviour of slurries. Viscosity nearly duplicates increasing the CNFs content to $2 \mathrm{wt} . \%$. CNFs-containing suspensions have a significant time dependency, especially those with $2 \mathrm{wt} . \%$ and higher solid content. Shape factor from CNFs rules an important effect in shear stress recovery by effects of orientation and expansion of CNFs during shear rate increase. ${ }^{26}$ At this solid content and $1 \mathrm{wt} . \%$ of CNFs a complex rheological behaviour is observed. At low shear rates a shear thinning is observed, while at higher rates there is a change to a shear thickening behaviour. For higher CNFs content ( $2 \mathrm{wt} . \%$ ) this complex behaviour is not observed.

The flow curves of the suspensions with 1 and 2 wt.\% CNFs prepared to a solids loading of $40 \mathrm{vol} . \%$ and different deflocculant concentrations are plotted in Fig. 7. These suspensions show a clear hysteresis cycle, especially for $2 \mathrm{wt}$ \% CNFs. However, the viscosities maintain very low while maintaining high solids loading, as desired for some processes such as spray drying, which has demonstrated to lead to much more homogeneous granules and hence, higher uniformity in the final thermal spray 

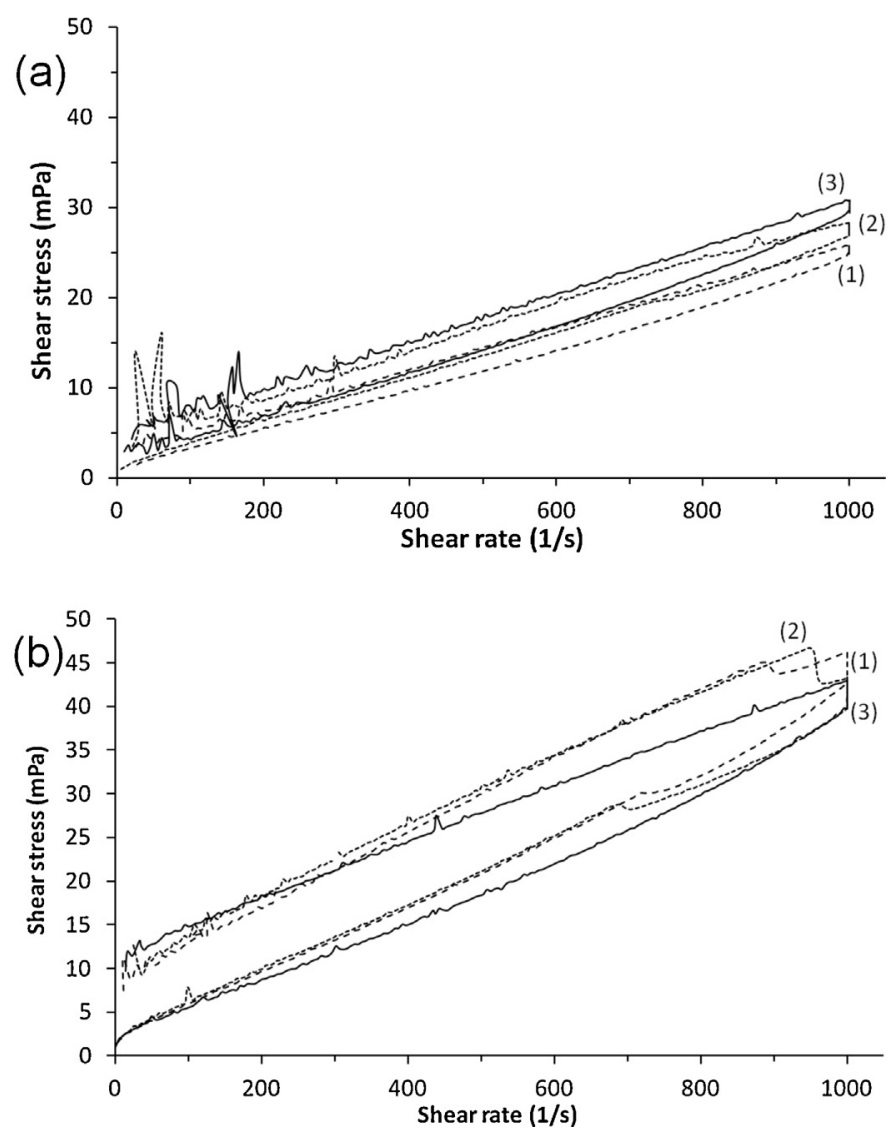

Fig. 7. Flow curves of milled mullite-CNFs suspensions with (a) 1 wt. $\%$ and (b) $2 \mathrm{wt} . \%$ of CNFs prepared to 40 vol. $\%$ solids with (1) $0.8 \mathrm{wt} . \%$ PAA, (2) $1.0 \mathrm{wt} . \%$ PAA, and (3) 1.5 wt. $\%$ PAA.

Table 1

Viscosity values ( $\mathrm{mPas}$ ) of milled mullite-CNFs suspensions at a shear rate of $1000 \mathrm{~s}^{-1}$.

\begin{tabular}{llrrl}
\hline PAA (wt.\%) & Mullite (vol.\%) & \multicolumn{3}{c}{ CNFs (wt.\%) } \\
\cline { 3 - 5 } & & 0 & 1 & \multicolumn{1}{l}{2} \\
0.8 & 30 & 6.6 & 6.6 & 16.1 \\
\multirow{3}{*}{1.0} & 40 & 14.0 & 25.1 & 45.2 \\
& 30 & 6.3 & 7.9 & 15.9 \\
1.5 & 40 & 10.3 & 27.3 & 45.2 \\
& 30 & 5.7 & 7.8 & 15.8 \\
& 40 & 13.2 & 30.2 & 43.3 \\
\hline
\end{tabular}

coatings. ${ }^{27,28}$ Table 1 compares the viscosities at a shear rate of $1000 \mathrm{~s}^{-1}$ of all suspensions, just after preparation and after $24 \mathrm{~h}$ ageing. There are no significant changes of viscosity for this period of time in mullite-CNFs suspensions, thus demonstrating the stability of these suspensions.

Comparing mullite and mullite-CNFs suspensions, it is observed that the stability of mullite-CNFs suspensions with time improves. When increasing the CNFs content, the thixotropy slightly increases, and the time stability of aged suspensions increases considerably. Low PAA presence is needed to stabilize suspensions.

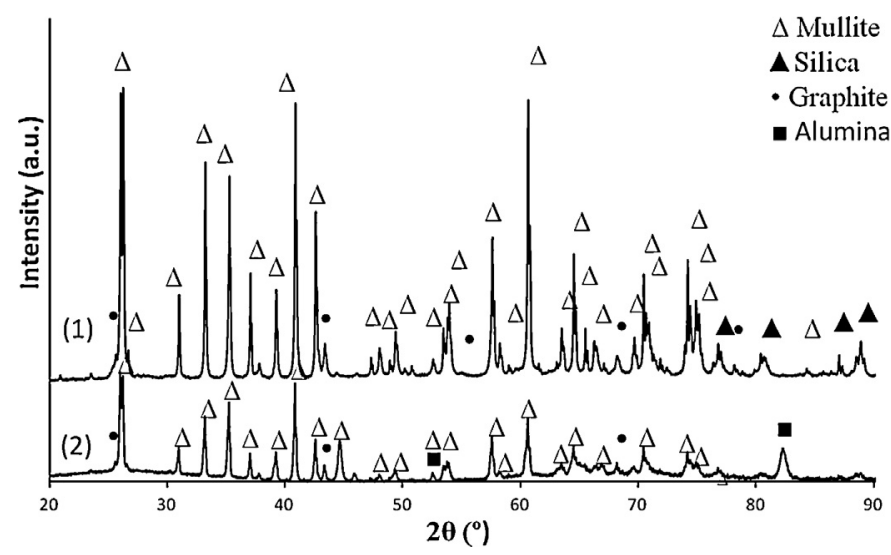

Fig. 8. XRD pattern of (a) spray dried mullite-CNFs powder and (b) thermal sprayed coatings.

\subsection{Preparation of spray dried granules}

The optimized mullite-CNFs suspension with $2 \mathrm{wt} . \% \mathrm{CNFs}$ and 40 vol. $\%$ solids was spray dried in the terms described in the experimental section. After spray drying, the shape, size, composition and structure of obtained granules were analyzed. Fig. 8a shows the XRD pattern of the agglomerated powder. Main phase of granules is orthorhombic mullite, although the presence of residual silica is still detected after agglomeration.

Comparing phases of initial milled mullite and agglomerates, there is no change of the phases present, although the peaks areas increase for granulated powder, which may be related to the higher particle size. The presence of CNFs is demonstrated by a peak broadening at $26^{\circ}\left[\begin{array}{ll}0 & 02\end{array}\right]$, and by peaks at $55^{\circ}$ and $78^{\circ} 2 \theta$ angle, that suggest CNFs bundles presence into agglomerates ${ }^{29}$. Peak at $44^{\circ}\left[\begin{array}{lll}1 & 1 & 0\end{array}\right]$ demonstrated nickel presence associated with CNFs.

The presence of carbon phase is confirmed by carbon elemental analysis, showing a content of $1.92 \pm 0.01 \mathrm{wt} . \%$ of carbon.

Fig. 9 shows the morphology of the spray dried granules as observed by FE-SEM at two different magnifications. At Fig. 9a, a general image of agglomerates is shown. Spray dried granules present nearly spherical shape, high porosity and broad granule size distribution consisting of low sized particles adhered to bigger ones, with diameters ranging from a few micrometres to around $100 \mu \mathrm{m}$. As it is shown in Fig. 9b, the presence of small holes in the granules is observed. High agglomerates porosity is expected from the use of submicronic raw materials. ${ }^{30}$ The broad particle size distribution of the granules observed in Fig. 9a is confirmed by the particle size distribution measured by $\mathrm{LD}$ presented in Fig. 10. According to the laser diffraction measurements, there is a small fraction of free particles and/or very small agglomerates, and a large volume of granules (by 90\%) with diameters ranging between 50 and $100 \mu \mathrm{m}$.

\subsection{Preparation of thermal spray coatings}

After powder characterization, parameters for thermal spray were evaluated. Agglomerates were finally sprayed by APS at a theoretical plasma temperature of $11,000^{\circ} \mathrm{C}$. The thickness, 

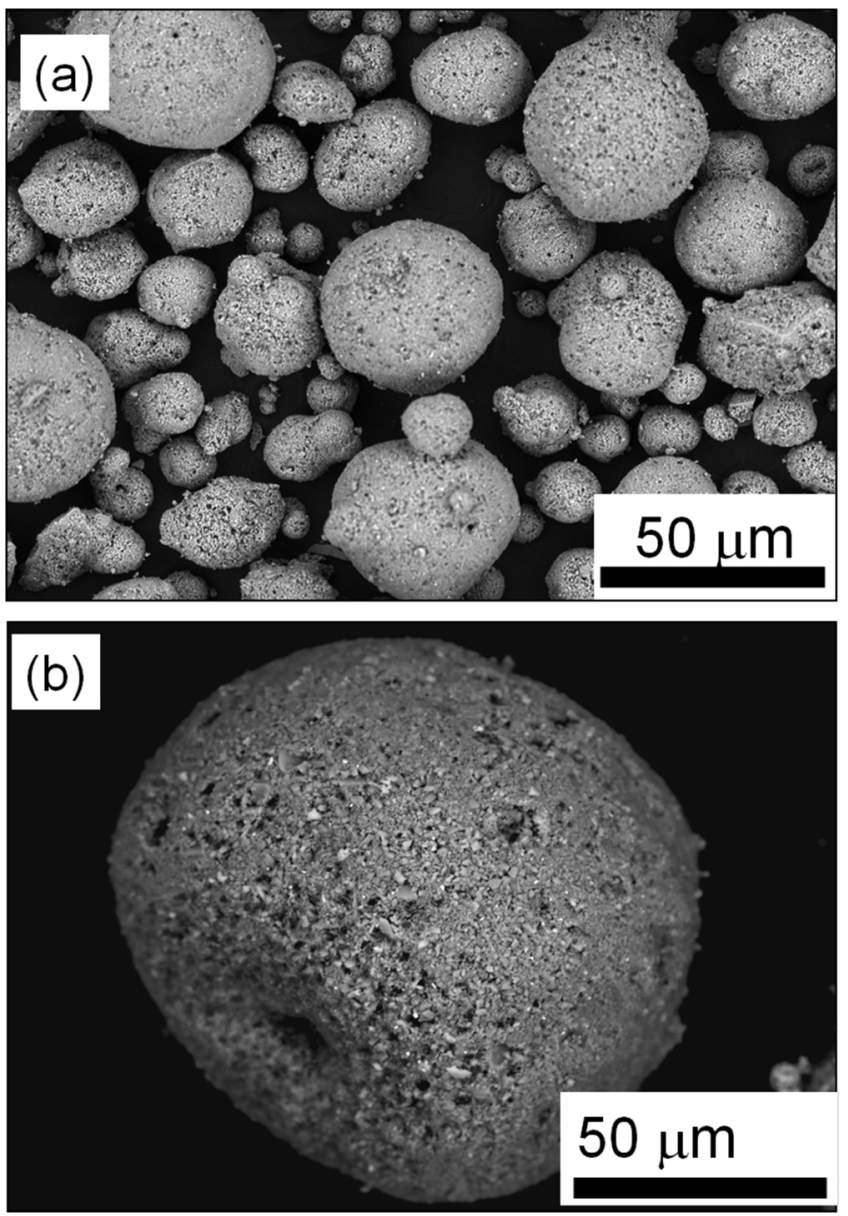

Fig. 9. FE-SEM images showing the morphology of spray dried granules at (a) lower and (b) higher magnification.

phases development, presence of carbon and adherence of the resulting coating were measured.

Fig. 11a shows a characteristic microstructure of a crosssection of the as-obtained coating. The coating is quite homogeneous along the sample, with a thickness of $54 \pm 10 \mu \mathrm{m}$ and no cracks are observed. Substrate-coating interface indicates a good adherence between surfaces. Tensile strength tests demonstrated that the coatings have an adherence of $59 \pm 6 \mathrm{MPa}$.

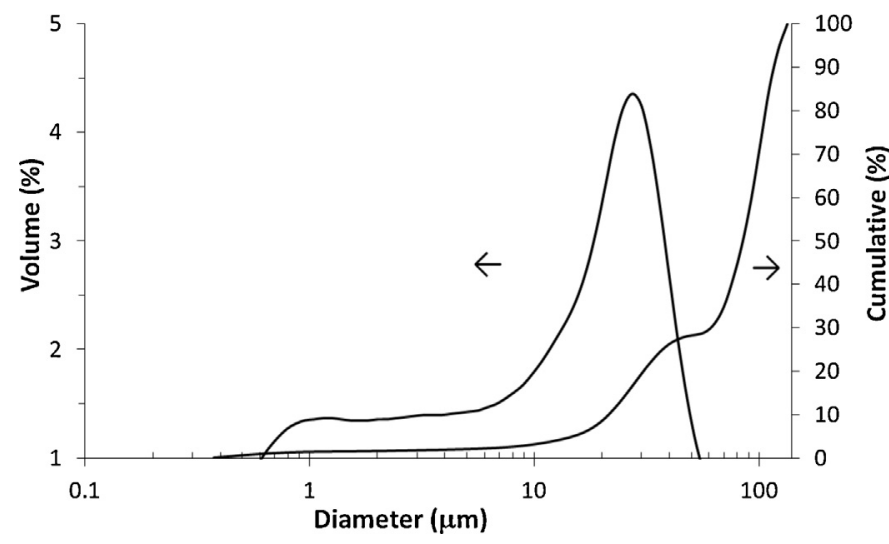

Fig. 10. Particle size distribution of mullite-CNFs spray dried granules measured by LD.
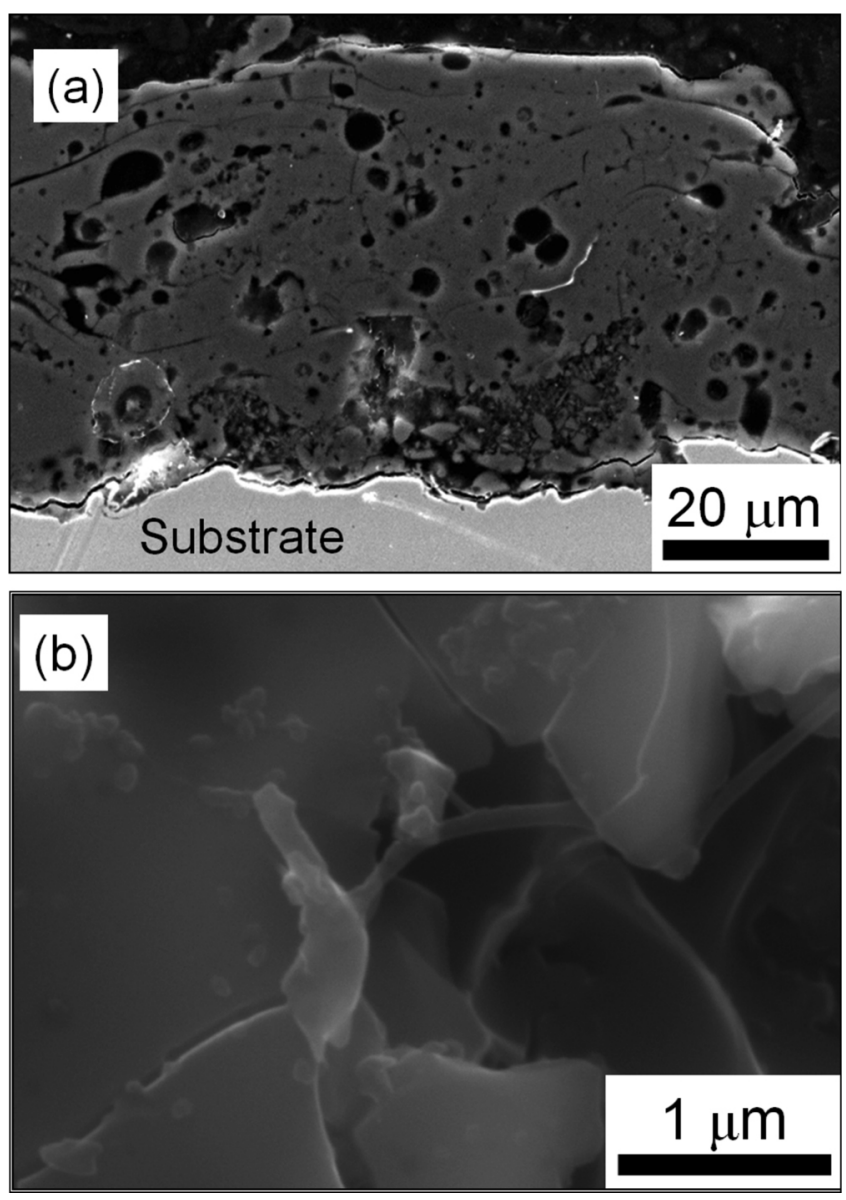

Fig. 11. FE-SEM images of mullite-CNFs coatings: (a) cross-sectional view, and (b) frozen and crushed surface section.

No peel out is observed by FE-SEM analysis. High porosity is observed in the coatings, as a result of the high porosity of the granulated powder. Porosity from final coating will be useful for their final use as thermal barrier and will by aim of interest in future works. ${ }^{31}$ To demonstrate the presence of entire carbon nanofibers, mullite-CNFs coatings were frozen with liquid nitrogen and crushed. Crushed coatings were analyzed by FESEM, showing the presence of entire CNFs inside coatings, as can be observed in Fig. 11b. The spraying reached a yield of $36 \pm 1 \%$, and further optimization of the spraying conditions need a specific study that is outside of the scope of the present research, although it could be the aim of interesting future work.

Fig. 8 compares the XRD patterns obtained for both the plasma sprayed coatings (Fig. 8b) and the original granules before APS (Fig. 8a). After the plasma spray process, the presence of silica is not detected, and rhombohedral alumina phase is detected as demonstrated by the reflections at $53^{\circ}\left[\begin{array}{lll}1 & 1 & 3\end{array}\right]$ and

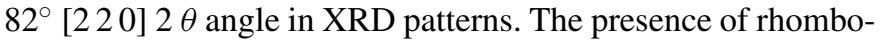
hedral phase of alumina is associated with process from mullite crystallization, indicating segregation of alumina in the silica amorphous phase. ${ }^{32}$ Amorphous phases in mullite are predicted by Miller ${ }^{33}$ and Kramer et al..$^{34}$ as a result of plasma spraying at temperatures higher than $1000^{\circ} \mathrm{C}$. These amorphous phases generate cracks in the coatings after exposure to thermal cycles in service. The CNFs are added to decrease the presence of

Please cite this article in press as: Rodríguez D, et al. Rheological behaviour of submicron mullite-carbon nanofiber suspensions for Atmospheric Plasma Spraying coatings. J Eur Ceram Soc (2013), http://dx.doi.org/10.1016/j.jeurceramsoc.2013.07.019 
cracks although an exhaustive study of cracks development and behaviour will be studied in future work.

\section{Conclusions}

In this work, concentrated suspensions of mullite and mullite-CNFs have been prepared and optimized to obtain uniform granules by spray drying to produce thermal spray coatings. From the colloidal studies, it was observed that both the starting milled mullite powder and the CNFs show the isoelectric point (IEP) at around $\mathrm{pH} 3$. However, when moving far from the IEP, the zeta potential values maintain relatively low. Thus, the presence of a polyacrylic-based deflocculant (PAA) leads to enhanced values of zeta potential assuring a high stability for both raw materials and their mixtures at $\mathrm{pH}>7$. The presence of PAA has a direct effect on the viscosity of the suspensions. A 2 wt. $\%$ of CNF can duplicate the viscosity and shear stress of mullite-CNF suspensions. The CNFs randomly distribute inside the matrix of mullite powders and the deflocculant preserves stabilization with time.

The optimized suspension with 40 vol. $\%$ solids and 2 wt. $\%$ CNFs was spray dried leading to spherical granules with a broad size distribution, where $90 \%$ of the granules had sizes ranging from 50 to $100 \mu \mathrm{m}$. The analysis performed by XRD and FE-SEM showed that the CNFs are homogeneously distributed all along the granules. The coating obtained by APS is quite homogeneous along the sample, with a thickness of $54 \pm 10 \mu \mathrm{m}$ and without cracks. Substrate-coating interface indicates a good adherence between surfaces.

\section{Acknowledgements}

Authors want to bravely acknowledge the help from Grupo Antolin, Elsufa trading SL, Institute of Ceramic Techonoly (ITC) - Jaume I University (UJI) and financial support from projects 2009SGR00310 and MAT2012-31090 (Ministerio de Educación y Competitividad, Spain).

\section{References}

1. Somiya S, Davies RF, Pask JA. Mullite and mullite matrix composites ceramic transactions. Westerville, $\mathrm{OH}$, USA: American Ceramic Society; 1990

2. Aksay IA, Dabbs DM, Sarikaya M. Mullite for structural, electronic, and optical applications. J Am Ceram Soc 1991;74:2343-58.

3. Sacks MD, Lee HW, Pask JA. A review of powder preparation methods and densification procedures for fabricating high density mullite. In: Somiya S, Davies RF, Pask JA, editors. Mullite and mullite matrix composites, ceramic transactions, 6. Westerville, OH, USA: American Ceramic Society; 1990. p. 167-207

4. Schneider H, Schreuer J, Hildmann B. Structure and properties of mullite-A review. J Eur Ceram Soc 2008;28:329-44.

5. Schrijnemakers A, Andre S, Lumay G, Vandewalle N, Boschini F, Cloots R, Vertruyen B. Mullite coatings on ceramic substrates: stabilisation of $\mathrm{Al}_{2} \mathrm{O}_{3}-\mathrm{SiO}_{2}$ suspensions for spray drying of composite granules suitable for reactive plasma spraying. J Eur Ceram Soc 2009;29:2169-75.

6. Moya JS, Osendi MI. Microstructure and mechanical properties of mullite/ZrO 2 composites. J Mater Sci 1984;19:2909-14.

7. Becher PF. Microstructural design of toughened ceramics. J Am Ceram Soc 1991;74:255-69.
8. Khare R, Bose S. Carbon nanotube based composites - A review. J Min Mater Charact Eng 2005;4:31-46.

9. C. Merino, P. Soto, Furnace and procedure of carbon fibres, and the fibre thus obtained. European Patent Application 04381014 (2005).

10. Zhong W, Qi X, Deng Y, Yang Y, Qin C, Au C, Du Y. Controllable and largescale synthesis of carbon nanofibers, bamboo-like nanotubes, and chains of nanospheres over $\mathrm{Fe} / \mathrm{SnO}_{2}$ and their mcrowave-absorption properties. JPhys Chem C 2010;11:808-14.

11. Harikrishnan G, Singh SN, Kiesel E, Macosko CW. Nanodispersions of carbon nanofiber for polyurethane foaming. Polymer 2010;51:3349-53.

12. Lillo-Rodenas MA, Barranco V, Linares-Solano A, Oya A, Pico F, Ibañez J, Agullo-Rueda F, Amarilla JM, Rojo JM. Amorphous carbon nanofibers and their activated carbon nanofibers as supercapacitor electrodes. J Phys Chem C 2010;114:10302-7.

13. Zapata-Solvas E, Gómez-García D, Domínguez-Rodríguez A. Towards physical properties tailoring of carbon nanotubes-reinforced ceramic matrix composites. J Eur Ceram Soc 2012;32:3001-20.

14. Borrell A, Rocha VG, Torrecillas R, Fernández A. Improvement of carbon nanofibers $/ \mathrm{ZrO}_{2}$ composites properties with a zirconia nanocoating on carbon nanofibers by sol-gel method. J Am Ceram Soc 2011;94:2048-52.

15. Garmendia N, Santacruz I, Moreno R, Obieta I. Slip casting of nanozirconia/MWCNT composites using a heterocoagulation process. J Eur Ceram Soc 2009;29:1939-45.

16. Gonzalez-Julian J, Miranzo P, Osendi MI, Belmonte M. Carbon nanotubes functionalization process for developing ceramic matrix nanocomposites. $J$ Mater Chem 2011;21:6063-71.

17. Faure B, Lindeløv JS, Wahlberg M, Adkins N, Jackson P, Bergström L. Spray drying of $\mathrm{TiO}_{2}$ nanoparticles into redispersible granules. Powder Technol 2010;203:384-8.

18. Vicent M, Bannier E, Benavente R, Salvador MD, Molina T, Moreno R, Sánchez E. Influence of the feedstock characteristics on the microstructure and properties of $\mathrm{Al}_{2} \mathrm{O}_{3}-\mathrm{TiO}_{2}$ plasma-sprayed coatings. Surf Coat Technol 2013;220:74-9.

19. Vicent M, Sánchez E, Moreno A, Moreno R. Preparation of high solids content nanotitania suspensions to obtain nanostructured spray-dried powders for atmospheric plasma spraying. J Eur Ceram Soc 2012;32: 185-94.

20. Melero H, Dosta S, Fernández J, Guilemany JM. Characterization of new bioactive coatings of hydroxyapatite and $\mathrm{TiO}_{2}$ obtained by high-velocity oxy-fuel. Bol Soc Esp Ceram Vidr 2011;50:59-64.

21. Lee JH, Pi-Chuen T, Chang CL. Microstructure and thermal cyclic performance of laser-glazed plasma-sprayed ceria-yttria-stabilized zirconia thermal barrier coatings. Surf Coat Technol 2008;202:5607-12.

22. Roncari E, Galassi C, Bassarello C. Mullite suspensions for reticulate ceramic preparation. J Am Ceram Soc 2000;83:2993-8.

23. Hashi Y, Senna M. Relationship between rheological properties of slurries and pore size distribution of cast and compressed compacts of mullite. Powder Technol 1995;83:187-91.

24. Moreno R, Moya JS, Requena J. Rheological parameters of mullite aqueous suspensions. In: Vincenzini P, editor. Proceedings of the seventh international meeting on modern ceramics technology, materials science monographs, vol. 66B. Ceramics today-tomorrow's ceramics. Amsterdam, The Netherlands: Elsevier Science; 1991. p. 1053-61.

25. Burgos-Montes O, Moreno R. Colloidal behaviour of mullite powders produced by combustion synthesis. J Eur Ceram Soc 2007;27:7-4751.

26. Guilemany JM, Dosta S, Nin J, Miguel JR. Study of the properties of WC-Co nanostructured coatings sprayed by high-velocity oxyfuel. J Therm Spray Technol 2005;14:405-13.

27. Xu J, Chaterjee S, Koelling KW, Wang Y, Bechtel SE. Shear and extentional rheology of carbon nanofibers suspensions. Rheol Acta 2005;44:537-62.

28. Lumay G, Vandewalle N, Bodson C, Delattre L, Gerasimov O. Linking compaction dynamics to the flowproperties of powders. Appl Phys Lett 2006;89:093505

29. Weisenberger M, Martin-Gullon I, Vera-Agullo J, Varela-Rizo H, Merino C, Andrews R, Qian D, Rantell T. The effect of graphitization temperature on the structure of heical-ribbon carbon nanofibers. Carbon 2009;47:2211-8.

30. Sánchez E, Vicent M, Moreno A, Salvador MD, Klyastina E, Bonache V, Moreno R. Preparation and spray-drying of nanoparticle $\mathrm{Al}_{2} \mathrm{O}_{3}-\mathrm{TiO}_{2}$ 
suspensions to obtain nanostructures coatings by APS. Surf Coat Technol 2010;205:987-92.

31. Padture NP, Gell M, Jordan EH. Thermal barrier coatings for gas-turbine engine applications. Science 2002;296:280-4.

32. Cividanes LS, Campos TMB, Rodrigues LA, Brunelli D, Thim GP. Review of mullite synthesis routes by sol-gel. J Sol-Gel Sci Technol 2010;55:111-25.
33. Miller RA. Thermal barrier coatings for aircraft engines: history and directions. J Therm Spray Technol 1997;6:35-42.

34. Kramer S, Yang J, Levi CG. Thermochemical interaction of thermal barrier coatings with molten $\mathrm{CaO}-\mathrm{MgO}-\mathrm{Al}_{2} \mathrm{O}_{3}-\mathrm{SiO}_{2}$ (CMAS) deposits. $J$ Am Ceram Soc 2006;89:3167-75. 